\title{
LA CONSTRUCCIÓN DE COMUNIDADES POLÍTICAS EN BAJA CALIFORNIA: EL PAPEL DE LOS ACTORES POLÍTICOS Y SOCIALES EN EL ESCENARIO DE LA ALTERNANCIA ${ }^{1}$
}

Rosa María González Corona ${ }^{2}$ y Luís Carlos López Ulloa ${ }^{3}$

RESUMEN. Este artículo tiene como objetivo contribuir al análisis de las comunidades políticas contemporáneas y a la comprensión del concepto de comunidad. Se hace un análisis cualitativo del rol jugado por actores políticos y sociales en la configuración de comunidades partidistas en Baja California en el contexto de la alternancia electoral. Dichas comunidades se caracterizan por tener intereses compartidos con propósitos diferenciados -mantenerse en el poder o tener mayor acceso a beneficios y programas sociales-; pero también por jugar un papel más crítico y determinante en la toma de decisiones en materia electoral.

Palabras clave: Comunidades partidistas, actores sociales, alternancia, ciudadanía, partidos políticos.

ABSTRACT. This article aims to contribute to the analysis of contemporary political communities and understanding the concept of community. A qualitative analysis of the role played by political and social actors in shaping partisan communities in Baja California in the context of the electoral alternation is made. These communities are characterized by having shared interests with different purposes -remain in power or have greater access to benefits and social programs interests-; but also to play a more critical and decisive role in making decisions on electoral matters.

Keywords: Partisan communities, social actors, electoral alternation, citizenship, political parties.

\footnotetext{
${ }^{1}$ El artículo forma parte de un estudio más amplio en el cual se pretende identificar el impacto de las acciones y programas sociales encaminados al desarrollo comunitario en el contexto de alternancia de los partidos políticos a nivel local; es decir, cuestionar de qué manera afecta la interacción entre partidos políticos, funcionarios públicos y promotores comunitarios en la (de) construcción de tejido social, en la (dis)continuidad de programas sociales, en el privilegio o exclusión de la participación de la comunidad en programas de desarrollo social, principalmente en periodos electorales en el marco de la alternancia partidista.

${ }^{2}$ Doctora en Ciencias Sociales con Especialidad en Estudios Regionales. Profesora-investigadora, Universidad Autónoma de Baja California, Facultad de Humanidades y Ciencias Sociales. Coordinadora de la Licenciatura en Sociología. Calzada Universidad 14418, Parque Industrial, Tijuana, CP. 22390, Tijuana, Baja California. rosa.maria.gonzalez.corona@uabc.edu.mx

${ }^{3}$ Doctor en Estudios del Desarrollo Global, Profesor-investigador, Universidad Autónoma de Baja California, Facultad de Humanidades y Ciencias Sociales. Calzada Universidad 14418, Parque Industrial, Tijuana, CP. 22390, Tijuana, Baja California. luis.lopez5@uabc.edu.mx
} 


\section{Introducción}

El presente artículo tiene como propósito analizar cómo se forman las comunidades políticas y cómo intervienen en la acción política. Si bien se ha documentado la participación electoral de la sociedad bajacaliforniana en el contexto de la alternancia política, poco se ha abordado acerca de quiénes y cómo construyen las comunidades partidistas en Baja California; además de contribuir en el estudio de estas interrogantes, también se tiene como propósito profundizar en cómo se involucran los individuos en la actividad política, y su proceso de identificación con una agenda partidista.

En concordancia con la definición de un sistema de partidos elaborada por Pasquino (2011:177), se parte del supuesto que en Baja California se cuenta con un sistema de partidos sólido, en tanto que existen al menos dos opciones que suscriben agendas político-electorales que son expuestas a evaluación por los ciudadanos en cada proceso electoral, que además participan y compiten y que ello tiene consecuencias electorales y gubernamentales.

Tras más de 25 años desde la primera alternancia política a nivel local en Baja California, cabe reflexionar acerca de las transformaciones internas en los partidos políticos que participan en las elecciones estatales y el impacto en la correlación de la fuerza electoral de cada uno de ellos, así como en el comportamiento y la construcción de la trayectoria de sus militantes, tanto dentro de los partidos políticos como en las comunidades.

\section{Metodología}

Los objetivos que esta discusión pretenden analizar el comportamiento de las comunidades partidistas frente al proceso de alternancia en las alcaldías y la gubernatura de Baja California. Así mismo, describir los factores que intervienen en la formación- transformación 
de actores sociales y políticos a partir de su participación comunitaria en el contexto de la alternancia partidista. ${ }^{4}$

Para tener una perspectiva más amplia de lo que ha sucedido con la participación de la sociedad en los procesos electorales a nivel local en los últimos 30 años en Baja California, se han realizado entrevistas con militantes de los partidos Revolucionario Institucional, Acción Nacional, de la Revolución Democrática, del Trabajo, Movimiento Ciudadano y MORENA. En las entrevistas se revisa su trayectoria partidista, su opinión sobre la participación de la sociedad en la transición política vivida en el estado así como los pendientes en nuestro sistema político-electoral a nivel local, siguiendo las líneas de participación electoral y participación de la sociedad civil.

Para el diseño del marco muestral, se elaboró una muestra representativa y no probabilística; para la identificación de actores políticos y selección de informantes clave, se basaron en los criterios de inclusión: (ex) Funcionarios de desarrollo social de las tres principales fuerzas políticas en Tijuana, Ensenada y Mexicali, actores políticos con antecedentes de participación en acciones comunitarias. El número de casos estuvo regido por la propuesta metodológica de saturación teórica.

Se contempló la búsqueda bibliográfica y hemerográfica para ubicar claramente el contexto de tres momentos históricos importantes: el primero con la instalación del Cabildo Popular de Mexicali; el segundo, la época de alternancia con las victorias electorales de Ernesto Ruffo en Ensenada en 1986 y en 1989 en la gubernatura; en 2004, con la victoria electoral de Jorge Hank en la alcaldía de Tijuana, tras 15 años de hegemonía panista.

Debido a que la estrategia metodológica es el análisis de la experiencia y percepción de los actores sociales estudiados así como la construcción de comunidades partidistas, uno de los

\footnotetext{
${ }^{4}$ A través de la investigación en su conjunto se pretende contribuir al análisis del impacto (ruptura-continuidad) de los programas sociales dirigidos a la intervención comunitaria en contexto de alternancia de partidos políticos. El análisis de la interacción de actores sociales y políticos en la construcción de la comunidad en el contexto de la alternancia en el estado de Baja California. Analizar la intencionalidad y sentido de experiencias de intervención comunitaria de instituciones y actores políticos de las tres principales fuerzas partidistas del Estado.
} 
principales retos que se presenta en este ejercicio es la contradicción que podría haber entre el discurso de lo que se dice y de lo que se hace.

\section{Antecedentes}

La transición política de 1989 en el gobierno de Baja California fue un parteaguas en la historia electoral de México, y en buena medida, también en la historia de la participación electoral; colocándose como un objeto de observación en los estudios políticos. De ahí que resulta pertinente identificar las características que definen a cada comunidad partidista -con diferencias y coincidencias en sus formas de hacer política- y su acción en torno a la alternancia. Los antecedentes en este trabajo de investigación rescatan el escenario de la experiencia de la alternancia política a partir de la década de los 80 , privilegiando la acción de actores políticos y de la sociedad civil.

En primera instancia, se parte del supuesto que la elección municipal en Mexicali en 1983 produjo la instauración del Cabildo Popular, frente a las acusaciones de fraude electoral en dicha elección denunciadas por el Partido Acción Nacional. En segundo lugar, en ese mismo proceso electoral, en Ensenada se reconoció la victoria de un candidato no priísta a la alcaldía, lo que marcó el inicio de la alternancia en el estado. Tercera, el cambio de partido político en la gubernatura de Baja California en 1989, que inicia la etapa de alternancias en las gubernaturas como lo señala Ugalde (2012: 37), en la cual también fue relevante el despliegue de una fuerte participación de la ciudadanía. Cuarta, la alternancia a nivel municipal generó un periodo en que los partidos políticos tuvieron que reconfigurar su militancia y replantear su posición frente a la nueva realidad político-electoral en la entidad.

Paralelo al escenario de partidos políticos en el contexto de alternancia en Baja California; la sociedad civil organizada logró instituir la participación social a través de la Ley de fomento a las actividades de bienestar y desarrollo social y la Ley de participación ciudadana del estado, de los subcomités y consejos municipales y estatales, de la formación de redes de organizaciones de la sociedad civil y de la participación de promotores comunitarios como gestores entre las necesidades comunitarias y los programas sociales (CEBC, 2001). 
Sin embargo, las propias organizaciones, líderes sociales y promotores comunitarios argumentan los obstáculos que han puesto funcionarios estatales y municipales, que limitan la participación ciudadana, entre los cuales destacan el veto a la Ley de Fomento, por parte del entonces gobernador panista Héctor Terán-Terán en la década de los 90; la desaparición de los subcomités de participación ciudadana y de los COPLADEM, así como la debatible forma de participación ciudadana en las acciones en comunitarias impulsadas a través de los programas y planes de desarrollo social gubernamentales.

En las elecciones generales de 1983 acontecieron dos hechos que marcaron el nuevo rumbo político en el estado. En la elección municipal de Ensenada se reconoció la victoria de David Ojeda, siendo un candidato no priísta, aunque ya había sido alcalde de esta ciudad por el Revolucionario Institucional. Mientras tanto, en la elección municipal en la capital del estado, el candidato panista Eugenio Elorduy impulsó la instauración del Cabildo Popular de Mexicali ante lo que Acción Nacional consideró como un fraude en esa elección. Ambos hechos se conjugaron para la posterior victoria electoral del panista Ernesto Ruffo en la alcaldía de Ensenada en 1986.

En la elección presidencial de 1988, Cuauhtémoc Cárdenas encabezando al Frente Democrático Nacional logró una victoria electoral en Baja California. Para la elección de gobernador de 1989 en el estado, el elector manifestó su apoyo a la candidatura del panista Ernesto Ruffo Appel. En ambos casos es evidente que el elector manifestó su interés de cambio buscando y apoyando una candidatura contraria al partido oficial. Este escenario explica el viraje "ideológico" del voto en los procesos electorales de un año a otro.

Lo sucedido en estas dos elecciones, aporta evidencias que permiten explicar este viraje, en buena medida podría pensarse que fue una respuesta a la decepción del bajacaliforniano frente a los gobiernos del partido que históricamente había gobernado. Tanto el Partido Acción Nacional, con larga trayectoria de participación política en el estado, como los partidos de izquierda, en conjunto con el Frente Democrático Nacional representados por Cárdenas, aprovecharon la oportunidad de retomar el descontento planteando una agenda de cambio. Pasquino (2011:19) nos ayuda a comprender el fenómeno cuando sostiene: 
Las oscilaciones porcentuales del voto dependen de factores que no pueden ser atribuidos a la crisis de los partidos más que en medida bastante limitada. Sin embargo, las oscilaciones, incluyendo las positivas, pueden ser interpretadas también como consecuencia de la incapacidad de los partidos de mantener una afiliación estable y como búsqueda, por parte de los electores, de nuevos interlocutores partidistas ante las repetidas decepciones.

En la elección federal intermedia de 1991, el Partido Acción Nacional logró varias victorias en las diputaciones federales en el estado y ganó la senaduría con Héctor Terán Terán. Hacia 1992 estuvieron en juego las cuatro alcaldías y las diputaciones locales, hay que destacar que para dicha elección se aplicó la reforma electoral impulsada por el entonces Gobernador Ernesto Ruffo, la cual contenía innovaciones importantes como el uso de una credencial de elector con fotografía.

En la elección presidencial de 1994, el Partido Revolucionario Institucional obtuvo triunfos electorales en todas las posiciones en juego. Con este resultado es evidente que el elector que participa en las elecciones juzga y valora la actuación de los gobiernos, pero también juegan las circunstancias del contexto en curso. ${ }^{5}$

Para la elección local de 1995 el PAN logró refrendar la gubernatura en la candidatura de Héctor Terán-Terán, quien pertenecía al panismo histórico en el estado, y quien previamente había fungido como Senador en 1991. Se mantuvo la hegemonía en Tijuana y por primera vez la alcaldía de Mexicali fue encabezado por un candidato de adscripción panista; todo ello según los conteos del Instituto Electoral y de Participación Ciudadana de Baja California (IEPCBC, 1995).

Nuevamente en 1997 fue el PAN quien dominó la mayoría de las diputaciones federales, y en 1998, mantuvo una hegemonía importante en las elecciones locales intermedias en la entidad.

Para la elección general del 2001, nuevamente el estado de Baja California fue representado en cuatro de las cinco alcaldías, incluyendo al ejecutivo estatal por candidatos panistas. Para

\footnotetext{
${ }^{5}$ Por ejemplo el candidato presidencial priísta, Ernesto Zedillo Ponce de León, públicamente decía que se había criado en sus primeros años en la ciudad de Mexicali, además en Tijuana en marzo de ese año se había dado el asesinato de Luis Donaldo Colosio Murrieta, candidato presidencial del PRI.
} 
Espinoza (2003) a pesar del alto abstencionismo que marcó esta elección, el PAN salió fortalecido de cierta manera en sus procesos de elección interna. Al mismo tiempo, la necesidad de formar cuadros para gobernar obligó a Acción Nacional a flexibilizar sus procesos de ingreso y facilitar la llegada de nuevos liderazgos. Inevitablemente se presentó un proceso de cambio y relevo generacional dentro del partido que no exigió la construcción de una amplia trayectoria partidista para llegar a una candidatura. Esto cobra sentido cuando Hernández Vicencio (2001:223) afirma:

Cuanto más institucionalizado se encuentre un partido, la participación en su seno será más de "tipo profesional". Por el contrario, cuanto menos institucionalizado sea un partido, la participación en su seno tenderá a ser más de "tipo civil".

En la elección de 2004 los electores aportaron evidencia empírica que nos hace suponer que efectivamente, hay una valoración de las acciones y resultados de los gobiernos. Este contexto permite comprender la victoria de Jorge Hank Rhon como candidato del PRI a la alcaldía de Tijuana y de Samuel Ramos Flores en Mexicali. Para el caso de Tijuana se rompe la hegemonía panista de 15 años, mientras que para Mexicali el Revolucionario Institucional vuelve a encabezar el gobierno municipal después de 9 años. ${ }^{6}$

Podemos identificar en los resultados de esta elección indicadores que apuntan a concebir al elector bajacaliforniano con tendencias que se dirigen a la alternancia. Ésta se caracteriza según Pasquino (2001:185). “"por un movimiento pendular periódico y presenta pocos problemas, excepto el de su instauración, mucho más probable en sistemas efectivamente bipartidistas, o bien con dinámica concretamente bipolar”.

En la elección general del año 2007, es evidente ya el relevo generacional en Acción Nacional y en el Revolucionario Institucional. Las candidaturas a gobernador presentadas por ambos partidos en las figuras de José Guadalupe Osuna Millán y Jorge Hank Rhon, respectivamente, demuestran con su corta trayectoria política que los nuevos militantes controlan los aparatos partidistas. Destaca también las alianzas que ambos partidos establecieron con partidos locales como el Partido Encuentro Social o el Partido Estatal de Baja California, con el

\footnotetext{
${ }^{6}$ Según los resultados electorales, Jorge Hank obtuvo 138,230 votos frente a los 134,428 votos logrados por el panista Jorge Ramos (IEPCBC, 2004).
} 
objetivo de presentar una agenda política relativamente incluyente de sectores sociales específicos. Asimismo, se observa un bipartidismo en las alcaldías, Acción Nacional representa las alcaldías de Tijuana, Mexicali y Tecate, mientras que Ensenada y Rosarito son representadas por el Revolucionario Institucional.

En la elección del 2010, el PRI logró un reposicionamiento muy importante al conquistar las cinco alcaldías en juego y la mayoría en el congreso estatal, esto de acuerdo a los números del Instituto Electoral y de Participación Ciudadana de Baja California. Ante esta situación, el gobernador Osuna Millán tuvo que establecer negociaciones con los alcaldes y diputados locales priístas para mantener la gobernabilidad e impulsar su agenda de gobierno.

Para la elección de gobernador en 2013, Francisco Vega de Lamadrid encabezó una alianza entre Acción Nacional y el Partido de la Revolución Democrática ${ }^{7}$ frente al candidato del PRI, Fernando Castro Trenti. Además, se destaca la posición de los electores por tomar decisiones bipartidistas, gobernador panista junto a alcalde priísta en Tijuana (IEPCBC, 2013).

\section{Participación social y electoral en el contexto de la alternancia}

Los antecedentes de la alternancia política durante los últimos 30 años, expuestos en el apartado anterior nos permite identificar por una parte, elementos que responden específicamente a la participación electoral de los ciudadanos durante las jornadas electorales que determinan al candidato y partido político que logra obtener la mayoría en las contiendas en cuestión. Y por otra parte, este contexto delinea la configuración de comunidades políticas en la interacción de la participación política electoral y la participación social.

Baja California se identifica en la historia política y electoral de México como un laboratorio, en el cual se ha establecido el paradigma de la participación electoral como equivalente de la participación ciudadana sin que necesariamente signifiquen lo mismo. La primera se refiere particularmente a la participación en las urnas, garantizando con ello la legitimidad de la elección, puesto que las leyes electorales no definen un mínimo de votación; mientras que la

\footnotetext{
${ }^{7}$ Por primera ocasión en la historia electoral del Estado, el PAN y el PRD integraron una alianza electoral, acompañándose del Partido Estatal de Baja California y el Partido Nueva Alianza.
} 
segunda se relaciona sobre todo con la presencia de grupos de la sociedad civil en la resolución o discusión de diversos temas de la agenda pública de la ciudad, el estado o la nación.

Los resultados muestran por una parte, la percepción de los actores políticos sobre su consideración en torno a la participación de la sociedad civil en la transición política. Por otra parte, se analiza la percepción de promotores comunitarios y su relación con el partido y/o candidato en periodos electorales. Ambos nos permiten identificar los factores que intervienen en la configuración de comunidades políticas y en la formación transformación de los actores sociales y políticos.

El análisis se realiza a partir de testimonios compartidos por los actores políticos, los cuales tienen en común haber logrado ocupar un puesto de elección popular tales como gobernador, alcalde, diputado local, diputado federal y regidor, condición que les permitió tener la oportunidad de escuchar de viva voz las exigencias de la sociedad. A continuación se enumeran diez líneas:

Primera, la condición de Baja California como estado receptor de migrantes del resto del país genera una cultura de alta participación que se puede ver reflejada en las elecciones. De acuerdo a la percepción de los actores políticos esta situación se atribuye a la libertad económica que ha logrado la ciudadanía, la cual le permite preguntarse por quién será gobernado:

“... estas situaciones políticas (...), son promovidas por esa libertad que adquiere el hombre cuando tiene libertad económica, cuando ya no depende de la dádiva, $o$ del cacique o del partido político "X", si no que ya ellos comen con lo que ellos ganan con su trabajo y eso, insisto, da una fortaleza impresionante, aquí y en cualquier parte del mundo, y en cualquier parte de la historia de la humanidad y por lo tanto teniendo esa libertad económica empiezan a decir: yo quiero saber quién va a ser el alcalde, quién va a ser el gobernador, quién va a ser el presidente, quién va a ser el diputado..." (PAN- E. Elorduy, comunicación personal, 21 de marzo del 2014).

Entre el discurso del actor político y el promotor comunitario prevalece la contradicción, mientras que el primero argumenta que la participación política se debe a la libertad económica que convierte al ciudadano libre de tomar sus decisiones, el segundo argumenta 
que es precisamente la necesidad material y económica que dirige al líder de la comunidad a participar tanto en periodos electorales como fuera de ellos.

Segunda, se observó que entre los mecanismo desarrollados por actores políticos durante su gestión pública, utilizan espacios que facilitan el dialogo y la promoción para la interacción entre el actor político y el ciudadano o el promotor comunitario. Tal fue el caso en Mexicali que al instituirse, el "miércoles ciudadano", en formato de sesiones públicas de encuentro entre los servidores públicos y los ciudadanos (...) con la riqueza de la expresión de la comunidad (...)" y había un gran interés de la sociedad por participar en la promoción y realización de obras comunitarias (PAN- E. Elorduy, comunicación personal, 21 de marzo del 2014).

Tercera, la regulación y acceso a recursos públicos limita la participación del ciudadano común; en otras palabras, se deriva un problema en la participación de la sociedad civil: "muchas organizaciones de la sociedad civil inician sus actividades con un gran empuje y que se han (...) generado muchas instituciones intermedias, pero pareciera que el objetivo es generar una institución que reciba recursos del erario público"; el problema de ello es que al establecer regulaciones a la participación, al ciudadano se le limita su libertad pues están restringidas por una subvención gubernamental (PAN- P. Contreras, comunicación personal, 15 de febrero del 2014).

Cuarta, al menos en los últimos 30 años de procesos electorales en Baja California la franja de participación electoral se ha mantenido entre un 30 o 40\%, la cual se señala claramente como la “(...) franja de participación electoral de los partidos políticos y la sociedad pareciera ser que no se motiva, ni se incorpora". Para Barbosa Castillo la clave es abrir verdaderamente los espacios de participación y representación para que la sociedad cuente con instrumentos jurídicos que le permitan decidir sobre los temas de la cosa pública, y no solamente en los procesos electorales (PRI- C. Barbosa, comunicación personal, 31 de marzo del 2014). 
Quinta línea, se argumenta que el modelo de democracia participativa está agotado:

“(...) para transitar a una democracia participativa cuyo modelo no ha sido instaurado, por lo que se aprecia un problema de transición en el modelo democrático. Sin embargo, hay algunos elementos como la reforma política nacional, las reformas en Baja California, en la constitución en donde se le quita a los partidos la exclusividad de presentar candidaturas, condición que seguramente generará resistencias de aquellos que quisieran que el régimen continuara en manos de los partidos políticos. Si le damos paso a la democracia participativa, esto hará que sean mejores. Solo aquellos que no entiendan las exigencias de la sociedad estarán en contra de las reformas y deben entender que los partidos son organizaciones de ciudadanos. Estamos hablando de incorporar a la sociedad a los regímenes de representación y aunque hay algunas herramientas la sociedad aún no las utiliza" (PRI- C. Barbosa, comunicación personal, 31 de marzo del 2014).

Sexta, son las sociedades las que hacen los cambios al ir a las urnas. Desde el punto de vista de la priista Franciscana Krauss, la comunidad al participar ordena e impulsa los cambios que las necesidades van planteando, pues afirma: "somos nosotros los que marcamos, definitivamente, el cien por ciento, somos los responsables de esos cambios definitivamente" (PRI- F. Krauss, comunicación personal, 03 de marzo del 2014).

Séptima, la participación de la sociedad en la transición política "no era por una cuestión ideología, era un ánimo de hartazgo”. En este orden de ideas se requiere apertura ideológica en el ánimo de partir de su experiencia partidista y de contar con militantes más profesionales (PRD- A. Duarte, comunicación personal, 06 de junio del 2014).

Octava, también los partidos al llegar al gobierno corren el riesgo de desdibujarse pues se construyen en su entorno muchos intereses que no necesariamente coinciden con su agenda política (PRD- A. Duarte, comunicación personal, 06 de junio del 2014).

Novena, la sociedad civil de Baja California ha sido participativa y lo demostró claramente en los procesos. Uno de los problemas que enfrenta el sistema de partidos es que ha habido votaciones en el Estado con $28 \%$ de participación, condición que lleva a pensar en otras alternativas, lo cual se atribuye a que la sociedad se ha alejado de las urnas, al no ver que los cambios no prosperan y que impera la lógica de gobiernos tradicionales (PRD- J. González, comunicación personal, 02 de junio del 2014). 
Décima, en otros sistemas democráticos todas las enmiendas y propuestas pasan por las urnas, aquí no. Una vez que llegan los candidatos a ocupar un puesto de elección se olvidan de quien los llevó al poder, no hay instrumentos para que el ciudadano vaya evaluando el comportamiento de su funcionario público, no hay revocación de mandato. Los partidos políticos tienen una asignatura pendiente en el tema y la ciudadanía ha respondido no participando.

\section{Conclusiones}

Tomando en cuenta estas líneas en la participación social y política en el contexto de la alternancia, se derivan dos bloques que cruzan por todos los partidos políticos: los que ven desde la perspectiva optimista, que conciben a la participación como aquella que la sociedad manifiesta en las urnas, y aquellos que señalan que el ánimo de cambio y participación de la sociedad no es retribuido por los partidos políticos.

Cabe preguntarse entonces, ¿cuál es la relevancia para el elector bajacaliforniano de su participación constante si no ven reflejadas sus exigencias en las acciones de gobierno? Además, hay que cuestionar por qué los partidos políticos siguen subsistiendo como organizaciones públicas, Pasquino (2011: 193), señala que "los partidos son capaces de sobrevivir porque garantizan el funcionamiento del sistema político (...) Los partidos duran porque son los garantes, tanto cuando están en el gobierno como cuando están en la oposición, de una multiplicidad de intercambios políticos en sistemas en los que, una vez cesado el choque ideológico, hay una elevada y casi completa capacidad de negociación de intereses".

Los argumentos que presentan los actores políticos, llegan a suponer que la participación de los actores sociales ha favorecido la alternancia a nivel local, indistintamente favoreciendo a uno u otro partido político.

En este escenario, se entretejen negociaciones hacia el interior de los partidos, estás prácticas se vislumbran también en la interacción entre los partidos y los actores sociales. Las comunidades partidistas que se reconfiguran se caracterizan por intereses compartidos con 
propósitos diferenciados -mantenerse en el poder o tener mayor acceso a beneficios y programas sociales. Pero también se caracterizan por jugar un papel más crítico y determinante en la toma de decisiones en materia electoral. 


\section{Referencias}

Espinoza, A. "Alternancia política y gestión pública: el Partido Acción Nacional en el gobierno de Baja California”. México: El Colegio de la Frontera Norte. (1998).

Espinoza, A. - La transición difícil. Baja California 1995-2001. México: El Colegio de la Frontera Norte. (2003).

-CEBC, Congreso del Estado de Baja California. "Ley de Fomento a las Actividades de Bienestar y Desarrollo Social para el Estado de Baja California”. Recuperado el 21 de julio de 2014, (2001).

http://www.congresobc.gob.mx/Parlamentarias/TomosPDF/Leyes/TOMO_VI/Leybienestar 18MAR2016.pdf

-CEBC, Congreso del Estado de Baja California (2001). Ley de Participación Ciudadana del Estado de Baja California. Recuperado el 22 de julio de 2014, http://www.congresobc.gob.mx/Parlamentarias/TomosPDF/Leyes/TOMO_VI/Leyp articipa_21SEP2012.pdf

Hernández Vicencio, T. “De la oposición al poder”. El PAN en Baja California, 1986-2000. México: El Colegio de la Frontera Norte. (2001).

IEPCBC, Instituto Estatal y de Participación Ciudadana de Baja California.. Cómputo estatal de la elección de munícipes 2004. Recuperado el 21 de julio de 2004, (2004). http://www.iepcbc.org.mx/resultados.php

- (2014). Atlas de Resultados Electorales Federales 1991-2012. Recuperado el 21 de julio de 2014, http://siceef.ife.org.mx/pef2012/SICEEF2012.html\#

Loaeza, S. “Clases medias y política en México”. México: El Colegio de México. (1999). 
Meyer, L." El estado en busca del ciudadano: un ensayo sobre el proceso político mexicano contemporáneo”. México: Océano. (2005).

Mayer-Serra, C. "Por eso estamos como estamos. La economía política de un crecimiento mediocre”. México: Debate. (2011).

Meyer, L. "El estado en busca del ciudadano: un ensayo sobre el proceso político mexicano contemporáneo”. México: Océano. (2005).

Pasquino, G.” Nuevo curso de ciencia política”. Tr. De Clara Ferri. México: Fondo de Cultura Económica. (2011).

Piñera, D. “Interacción en la frontera México Estados Unidos”. 1900-1945. México: Asociación Iberoamericana de Estudios sobre Frontera. (1995).

Samaniego, M. A. “Breve historia de Baja California”. México: Miguel Ángel Porrua UABC. (2006).

Ugalde, L.C. “Por una democracia eficaz”. Radiografía de un sistema político estancando, 1977-2012. México, D.F.: Aguilar. (2012). 